\title{
Venlafaxine Caffeic Acid Salt: Synthesis, Structural Characterization, and the Hypoglycemic Effect Analysis
}

\author{
Hongmei Yu${ }^{1}$, Yong Zhang ${ }^{2}$, Cheng Xing ${ }^{1}$, Ying Wang ${ }^{1}$, Hailu Zhang ${ }^{3}$, Ningbo Gong1,*, Yang \\ Lu1,*, Guanhua Dư ${ }^{4}$. \\ 1 Beijing Key Laboratory of Polymorphic Drugs, Institute of Materia Medica, Chinese Academy \\ of Medical Sciences and Peking Union Medical College, Beijing 100050, China \\ 2 Hainan Medical University, Haikou 571199, China \\ 3 Laboratory of Magnetic Resonance Spectroscopy and Imaging, Suzhou Institute of Nano-Tech and \\ Nano-Bionics, Chinese Academy of Sciences, Suzhou 215123, China \\ 4 Beijing City Key Laboratory of Drug Target Identification and Drug Screening, Institute of \\ Materia Medica, Chinese Academy of Medical Sciences and Peking Union Medical College. \\ Beijing 100050, China.
}

Preparation of venlafaxine (VLF) from venlafaxine hydrochloride. To prepare a free base of VLF, VLF hydrochloride and sodium hydroxide were mixed at a definite stoichiometric ratio (1:1) in water. The resulting mixture was sufficiently stirred at $25{ }^{\circ} \mathrm{C}$ for $40 \mathrm{~min}$ to make sure that the reaction was completed. Then, ethyl acetate was added to extract the free base, and the organic phase was evaporated slowly under decompression conditions. The powder was recrystallized in hexane to acquire VLF crystal at room temperature for a week. The cell parameters are $a=8.4135(12) \AA, b=$ 8.8669(12) $\AA, c=21.7900(30) \AA, \beta=92.307(6)^{\circ}$, as described in the literature CCDC refcode OCALAG02 (Cambridge Crystallographic Data Center, Cambridge, UK).

Preparation of venlafaxine-caffeic acid salt (VLF-CA). VLF-CA was prepared using three different methods as described below.

Crystallization from Solution. VLF (55.4 mg, $0.2 \mathrm{mM})$ and CA (36.0 mg, $0.2 \mathrm{mM}$ ) were distributed in a solvent mixture of ethyl acetate and ethanol $(5 \mathrm{~mL})$ for crystallization. Raw materials were prepared inside a closed vial and heated to approximately $333{ }^{\circ} \mathrm{C}$, under magnetic stirring, until complete dissolution was achieved. The vial was placed at ambient temperature for seven days, to yield a precipitate from which well-formed VLF-CA crystals could be separated. 
Liquid-assisted grinding. VLF (277.4 mg, $1 \mathrm{mM})$ and CA (180.2 mg, $1 \mathrm{mM})$ were added into a mortar and ground by pestle for 10-15 min after 3-5 drops of ethyl acetate were added. The resulting powders were collected for characterizations.

Slurry. VLF (277.4 mg, $1 \mathrm{mM})$ and CA (180.2 mg, $1 \mathrm{mM}$ ) were suspended in ethyl acetate. The suspension was agitated at $500 \mathrm{~g}$ for $24 \mathrm{~h}$ at $40{ }^{\circ} \mathrm{C}$, and the agglomerates were filtered and dried in a $40{ }^{\circ} \mathrm{C}$ oven for 12 hours.

The HPLC method development and validation parameters. A high-performance liquid chromatography (HPLC) method to quantify the concentrations of VLF in the VLF-CA salt has been validated, including following parameters: specificity, linearity, precision, the Limit of Detection (LOD), and the Limit of Quantification (LOQ). The chromatography conditions were as follows: a Linksil-ODS $5 \mu \mathrm{m}(150$ $\mathrm{mm} \times 4.6 \mathrm{~mm}$ ) column; the mobile phase, acetonitrile and $0.1 \mathrm{~mol} \mathrm{~L}^{-1}$ potassium dihydrogen phosphate water solution $(32 / 68, v / v)$; flow rate, $1.0 \mathrm{~mL} \mathrm{~min}^{-1}$; column temperature, $35^{\circ} \mathrm{C}$; injection volume, $5 \mu \mathrm{L}$; detection wavelength, $225 \mathrm{~nm}$.

Preparation of sample stock solution. The VLF-CA sample stock solution $(1019 \mu \mathrm{g}$ $\mathrm{mL}^{-1}$ ) was prepared by dissolving an approriate amount of VLF-CA salt powders in the distilled water. Diluted sample stock solutions were used for determinations of linearity, specificity, precision, LOD and LOQ. All the concentrations were equivalent of VLF calculated according to molecular weights.

Linearity. Linearity was determinate injected six VLF-CA sample concentrations three times onto the HPLC. Concentrations of calibration samples were 2.0, 10.2, 20.4, 40.8, 101.9, and $203.8 \mu \mathrm{g} \mathrm{mL}^{-1}$. The linear calibration curve was constructed from peak area (y) and concentration (x), and the regression equation and the regression coefficient $(R)$ were calculated. $y=11.136 x+12.326, R=0.9992$. The results showed that an excellent correlation existed between the peak area and concentration, ranging from $2.0 \mu \mathrm{g} \mathrm{mL}^{-1}$ to $203.8 \mu \mathrm{g} \mathrm{mL}^{-1}$ (Figure S1). 


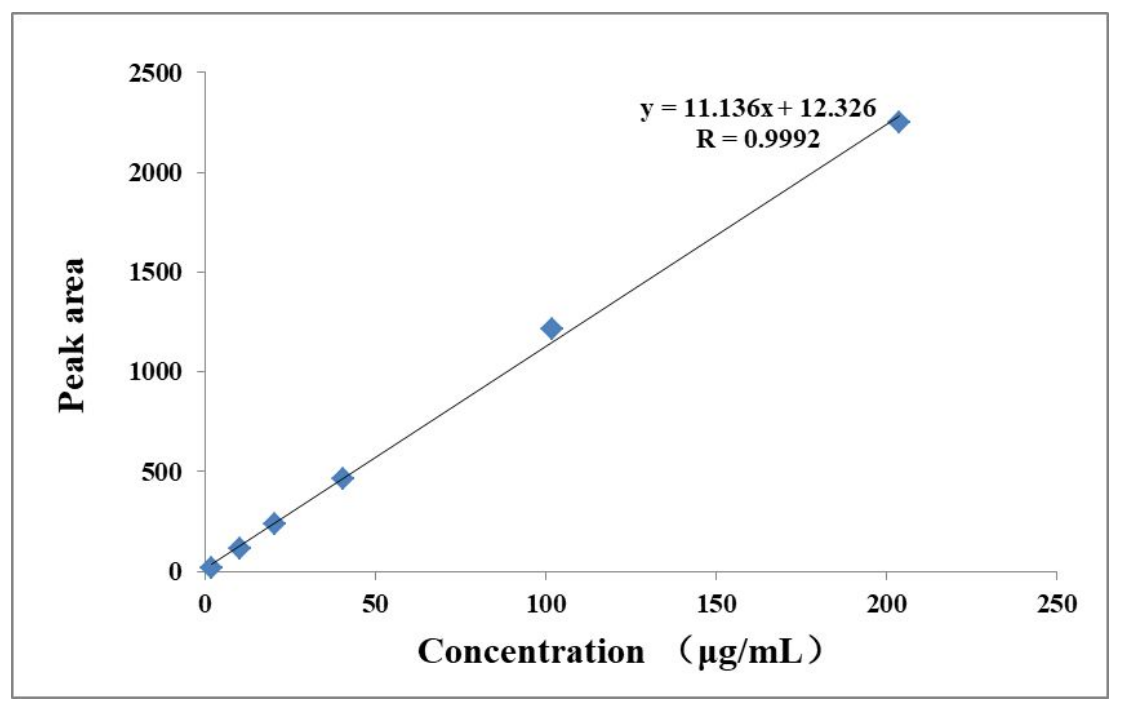

Figure S1 The calibration curve of the VLF-CA sample solution

Specificity. VLF-CA sample, VLF, and CA solution were injected respectively onto the HPLC. The retention times of CA and VLF were 1.64 and $2.86 \mathrm{~min}$, respectively. There was no endogenous peak observed in chromatograms at the retention times of VLF and CA (Figure S2).

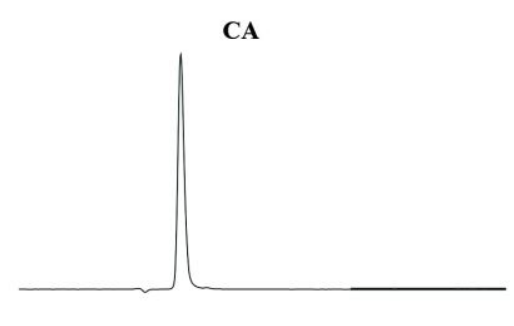

VLF
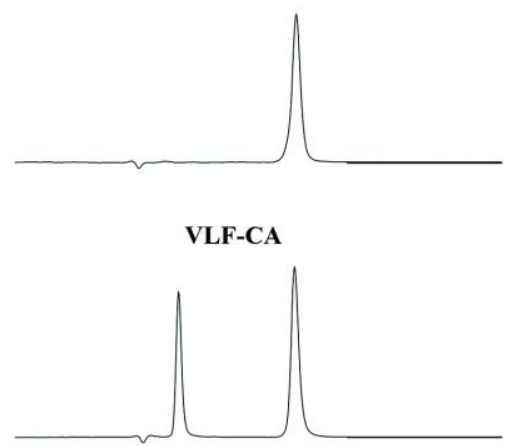

blank

Figure S2 The HPLC patterns of VLF-CA, blank solution, and raw materials 
Precision. Inter-day and intra-day precision were performed with three different concentrations $\left(10.2,40.8,203.8 \mu \mathrm{g} \mathrm{mL}^{-1}\right)$ of VLF-CA sample solutions injected six times. This procedure was repeated on three consecutive days and expressed as the mean, standard deviation (SD), and percentage relative standard deviation (\% RSD). \% RSD of VLF-CA sample solutions $\left(10.2 \mu \mathrm{g} \mathrm{mL}^{-1} 、 40.8 \mu \mathrm{g} \mathrm{mL}^{-1} 、 203.8 \mu \mathrm{g}\right.$ $\mathrm{mL}^{-1}$ ) were found to be $0.63 \%, 0.63 \%, 0.21 \%$, respectively within a day. The HPLC method was precise. The sample solutions were stable up to 3 days.

Table S1. Results of inter-day precision for the HPLC method evaluated with three different concentrations of VLF-CA solution

\begin{tabular}{cccccc}
\hline Nominal concentration & \multicolumn{5}{c}{ Mean of the peak area } \\
\cline { 2 - 5 }$\left(\mu \mathrm{g} \mathrm{mL}^{-1}\right)$ & day 0 & day 1 & day 2 & day 3 & \\
\hline 10.2 & 112.18 & 112.20 & 112.67 & 110.92 & 98.88 \\
40.8 & 465.13 & 455.28 & 451.40 & 451.03 & 96.97 \\
230.8 & 2255.43 & 2279.02 & 2252.33 & 2253.93 & 99.93 \\
\hline
\end{tabular}

$\mathrm{A}_{3} / \mathrm{A}_{0}(\%)^{\mathrm{a}}=($ mean of the peak area of day $3 /$ mean of the peak area of day 0$) \times 100$

Limit of Detection and Limit of Quantification. LOD and LOQ of the developed method were determined by injecting progressively low concentrations of the VLF-CA sample solutions using the developed HPLC method, based on the signal to noise ratio $(\mathrm{S} / \mathrm{N}) . \mathrm{S} / \mathrm{N}=3$ for $\mathrm{LOD}$, and $\mathrm{S} / \mathrm{N}=10$ for $\mathrm{LOQ}$. The $\mathrm{LOQ}$ for VLF was found to be $1.04 \mu \mathrm{g} \mathrm{mL}^{-1}$, and the LOD for VLF was found to be $0.52 \mu \mathrm{g} \mathrm{mL}^{-1}$. It was concluded that the developed HPLC method was sensitive.
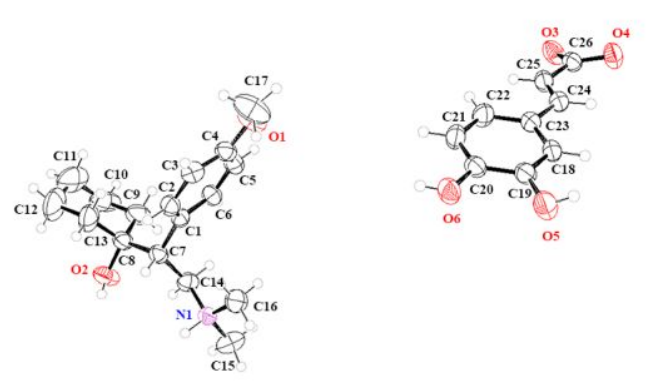
Figure S3 Ortep type view of the asymmetric unit with a 50\% probability ellipsoid

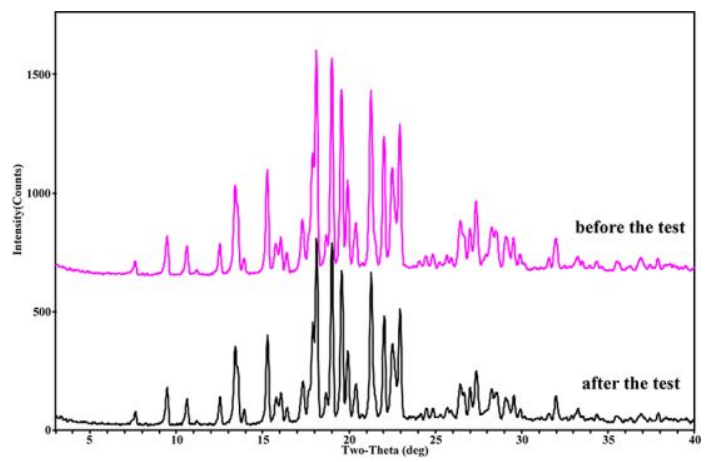

Figure S4 The PXRD patterns of VLF-CA salt before and after the long-term stability test
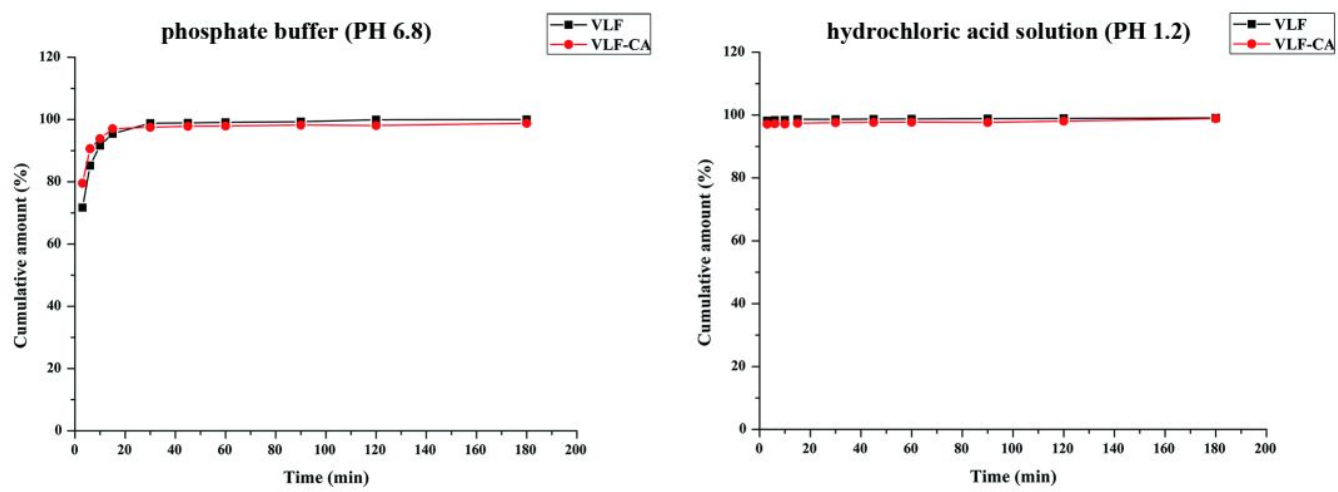

Figure S5 The dissolution profiles of VLF and VLF-CA in hydrochloric acid solution $(\mathrm{PH}=1.2)$ and phosphate buffer $(\mathrm{PH}=6.8)$. 